\title{
Funiculars anomalies during childbirth: about 562 cases collected in Pikine National Hospital
}

\author{
Moussa Diallo $^{1}{ }^{*}$, Abdoul Aziz Diouf ${ }^{1}$, Cire Espérance Koulimaya ${ }^{1}$, Niang Y. ${ }^{1}$, Astou Coly Niassy \\ Diallo $^{2}$, Mame Diarra Ndiaye ${ }^{2}$, Omar Gassama ${ }^{2}$, Niang M. ${ }^{2}$, Gueye M. ${ }^{2}$, Moreau J. C. ${ }^{2}$, Diouf A. ${ }^{1}$
}

\author{
${ }^{1}$ Department of Obstetrics and Gynecology, Centre Hospitalier National de Pikine Sis Camp de Thiaroye, Dakar, \\ Senegal \\ ${ }^{2}$ Department of Obstetrics and Gynecology, De l'Hôpital Aristide Le Dantec, Dakar, Senegal
}

Received: 28 September 2016

Revised: 06 October 2016

Accepted: 24 October 2016

\section{*Correspondence:}

Dr. Moussa Diallo,

E-mail: moussadiallo25@hotmail.com

Copyright: (C) the author(s), publisher and licensee Medip Academy. This is an open-access article distributed under the terms of the Creative Commons Attribution Non-Commercial License, which permits unrestricted non-commercial use, distribution, and reproduction in any medium, provided the original work is properly cited.

\begin{abstract}
Background: Establish an epidemiological description of the different types of umbilical cord anomalies in our reference structure and to assess their impact on the prognosis of childbirth.

Methods: We conducted a descriptive study, cross over a period of one year in Obstetrics and Gynecology Service Level III of Pikine Hospital. We included all women in labor have reached the term less than 28 weeks gestation and delivering a newborn with umbilical cord abnormality diagnosed during labor or during the expulsion.

Results: During this period, we compiled 562 anomalies of the umbilical cord, which gave a frequency of $23.8 \%$. Length discrepancies were far the most frequent $(67.4 \%)$. Only the prolapsed cord was an independent risk factor for cesarean section $(\mathrm{p}=0.036)$. The rate of episiotomy and tear was significantly higher in case of brevity (primitive or induced $)$ cord $(p=0.042)$. Apgar score $\leq 7$ was significantly related to the presence of brevity $(p=0.000)$, excessive length $(p=0.048)$ or cord prolapse $(p=0.037)$.

Conclusions: This study has allowed us to see that the funicular abnormalities impede the smooth running of childbirth. Their occurrence is facilitated by the excess amniotic fluid, prematurity and low birth weight. Their research during prenatal ultrasounds should be systematic.
\end{abstract}

Keywords: Anomalies funiculars, Childbirth, Dystocia, Prolapsed cord

\section{INTRODUCTION}

Abnormalities of the umbilical cord are responsible for the most frequent attacks during labor with disruption of the funicular flow, and thus the fetal-maternal exchanges and/or by hindering the delivery mechanism. ${ }^{1}$ This pathology has many features. Position anomalies often observable in the third trimester of pregnancy and during delivery (coiling funis, breech and prolapse); and constitutional anomalies, especially single umbilical artery and velamentous insertion on the other hand. ${ }^{2}$ However, the study of these diseases is inadequate epidemiologically, clinically, and prognostically as well, particularly in Africa. Our purpose in this work is to develop an epidemiological description of different types of umbilical cord abnormality in our reference center, and also to assess their impact on the prognosis of delivery.

\section{METHODS}

We conducted a descriptive, cross-sectional study for one year (1 January 2009 - 31 December 2009) in the level 3 obstetrics and gynecology care unit of the Pikine hospital (Dakar, Senegal). We included all women below 28 
weeks gestation, and who gave birth to a newborn diagnosed with umbilical cord problems during labor or during the expulsion. The main parameters studied were: patient's age, gynecological and obstetric history, gravidity, parity, quality of pregnancy monitoring, type of umbilical disorder, evolution and mode of delivery, maternal morbidity and fetal morbidity and mortality. Data were collected from patients' medical records. Statistical analyzes were performed using Epi Info software. The statistical tests used were the Chi-square test or Fisher's exact test. A p value of less than or equal to 0.05 was taken as statistically significant.

\section{RESULTS}

Out of 2363 births registered during this period, 562 had umbilical cord problems, i.e. a frequency of $23.8 \%$. As a whole, there were two types of problems: deformity (excessive length, short cord) in most cases (67.4\%), and abnormal course (coiling of funis, breech, prolapse, ventral decubitus and cord knot), about 32.6\%. All combined anomalies, excessive length of the cord was by far the most reported with $54 \%$, followed by the coiling of funis in $37.5 \%$ of cases, and the shortness of cord in $13.3 \%$ (Table 1). There was no significant link between placental abruption and short cord in our study $(\mathrm{p}=0.32)$. Cord prolapse, 8 cases, represented $1.4 \%$ of abnormalities. No vascular or velamentous abnormality was found. The average age of women in labor was 27 years with extremes of 14 and 47 years. The mean parity was 2 , with $65 \%$ of first-time mothers. Historically there were more abortions (56.9\%), cesarean (36.2\%) and hypertension $(5.3 \%)$. The average antenatal care was 3.8 . However, more than half of the patients had not received ultrasound (63.9\%) during the monitoring of pregnancy.

Table 1: Frequency of different types of funiculars abnormalities.

\begin{tabular}{|lll|}
\hline Umbilical cord anomalies & Effective & Percentage \\
\hline Excessive length & 212 & 37,7 \\
\hline Ciruclar & 136 & 24,2 \\
\hline Short length & 75 & 13,3 \\
\hline Slip road & 25 & 4,4 \\
\hline Prolapse & 10 & 1,8 \\
\hline Cord knot & 2 & 0,4 \\
\hline $\begin{array}{l}\text { Excessive length and } \\
\text { circular }\end{array}$ & 75 & 13,3 \\
\hline $\begin{array}{l}\text { Excessive length and Slip } \\
\text { road }\end{array}$ & 17 & 3 \\
\hline Circular and slip road & 6 & 1,1 \\
\hline Circular and short length & 3 & 0,5 \\
\hline Total & 562 & 100 \\
\hline
\end{tabular}

Spontaneous onset labor and cephalic presentation were reported in most cases ( $92.9 \%$ and $90.4 \%$ respectively). The frequency of breech presentation in our series was high $(8.7 \%)$ compared to the average of the general population. The main labor complication was fetal asphyxia. Nearly one third of the patients gave birth by cesarean section (33.3\%). The indications for the abdominal route were mostly fetal-pelvic disproportion $(30.2 \%)$, fetal asphyxia (13.8\%), and retro-placental hematoma (11.3\%). Prolapsed cord was the only independent risk factor for cesarean section $(\mathrm{p}=0.036)$. The average weight of newborn was $3020 \mathrm{gm}$, with extremes of $1800 \mathrm{~g}$ and $5600 \mathrm{~g}$. Low birth weight was found in $16 \%$. There was no maternal mortality. However, morbidity was mainly from episiotomy $(19.2 \%)$ and perineal laceration $(6.4 \%)$. The rate of episiotomy and perineotomy was significantly higher with short umbilical cord (primary or caused) $(\mathrm{p}=0.042)$. Stillbirth was $64 \%$. Apgar score $\leq 7$ was closely linked to shortness of umbilical cord $(\mathrm{p}=0.000)$, excessive length ( $\mathrm{p}=0.048)$, or cord prolapse $(\mathrm{p}=0.037)$. These abnormalities were related to $61.7 \%$ of neonatal deaths; there was a higher fatality rate with prolapse $(25 \%)$, and with short cord $(17.2 \%)$

\section{DISCUSSION}

\section{Frequency}

Funicular abnormalities are common but little studied. This is all the more true that the literature in this field does not seem to excite many people, in view of the scarce existing research on this subject. Yet, the impact on the perinatal condition, and to a lesser extent on the maternal state, must make it an obstetrical concern. The prevalence of funicular anomalies in our study (23.8\%) is by far higher than reported in the literature, particularly when quoting Djanhan, Cote d'Ivoire, with the rate of $8.9 \%$. $^{1}$

The higher frequency of excessively long cord (37.7\%) in our series is in line with the publications by other authors. ${ }^{1,2}$ Coiled funis was a quarter of our study sample $(24.2 \%)$, followed by short cord as described in the works of Shui and Eastman, and of Spellacy, with a frequency between 15 and $30 \%$. $^{3,4}$ Cord prolapse in our series $(1.9 \%)$ is higher than the figures from various authors $(0.4$ and $0.5 \%){ }^{5}$ However, 8 cases of cord prolapse we collected contrast with the $13 \%$ found by Djanhan. ${ }^{1}$ Knots represent $0.4 \%$ in our series, which corresponds to the work of Brown Benirschke and Spellacy where the prevalence is between 0.3 and $2 \% .^{4,6,7}$ The lack of finding constitutional anomalies can be explained by their scarcity confirmed by several authors like Fox Eberst and Merger. $2,8,9$

\section{Etiological factors}

Our work does not allow us to give examples of risk factors of funicular anomalies since we were not dealing with a case-control study. Nevertheless, in terms of cord prolapse, some of the risk factors mentioned in the literature are found therein in number of cases, i.e. excessively long cords $(75 \%)$ and hydramnios $(25 \%){ }^{1,2,10-12}$ Other factors involved in umbilical cord 
problems, such as high parity, twin pregnancy, abnormal presentation and low birth weight. However, they remain low in our series $(2.2 \%)$.

\section{Diagnosis}

The two-dimensional and Doppler ultrasound can greatly contribute to diagnosing prenatal umbilical cord complications, especially when these are connected with circulation (vascular), course or coiling. However, good competence is required from healthcare providers. During labor, the diagnosis can be made when some indirect signs are identified such as fetal asphyxia resulting in abnormal fetal heart rate, stagnating dilatation despite compensatory therapy, or lack of progress in fetal presentation. In all cases, umbilical cord problems are usually suspected during labor. The diagnosis is confirmed at the time of expulsion or immediately during postpartum period, or sometimes after anatomopathological examination of the placenta.

\section{Prognostic aspects}

Caesarean section rate $(33.3 \%)$ is high, but anyway comparable to on the annual average (35\%) that we keep on record in our reference facility. This proves that apart from the umbilical cord prolapse, funicular anomalies do not particularly provide for caesarean procedure. The rate of episiotomies (19.2\%) and perineal lacerations (6.4\%) were also similar to our records. A special situation may nevertheless contribute to shortening labor length if the diagnosis is known before birth, since the obstetrician tends to be fewer patients and more stressed. Shortness of the umbilical cord was associated, in $21.9 \%$, with newborns having an Apgar score greater than 7. This makes us think that this anomaly could be a bad fetal prognosis, because it could cause fetal asphyxia, which could be linked to two mechanisms: circulatory disturbance from stretched cord, or premature placental abruption due to repeated traction. ${ }^{11}$ As for prolapsed cord, reference is made to poor Apgar score in only 6.3\% of cases. However, the problems resulting from abnormal position of the cord greatly helped us identify high fetal morbidity in our series with $37.5 \%$ of fetal asphyxia. No fetal death in relation to breech presentation or knotted cord was found in our series. These results match those of Guikovaty who hardly noticed any fetal death in this situations.

Stillbirth in a short cord context was $26.3 \%$. This high rate compared to the findings by Djanhan $(6 \%)$ could be explained by late diagnosis of the disease. ${ }^{1}$ This has always been performed in our study at the time of expulsion.

The death rate at birth by cord prolapse was $4.8 \%$. This relatively low rate compared to Merger's data $(85 \%)$ could be explained by the quick cesarean section for the purpose of improving the fetal prognosis, given that the two deaths corresponded to cases of vaginal delivery. ${ }^{2}$
We recorded 11 cases of intrapartum fetal death in the context of coiling of funis, $26.3 \%$ of women in labor and $6.9 \%$ of coiled funis cases. This rate is still high, despite being well below those of Djanhan and Niacadie, $8.7 \%$ and $6 \%$ respectively, given that fetal death due to cord coiling is rare and requires confirmation by checking the presence of anatomical lesions features in the placenta. ${ }^{1,13}$ An imprint of the cord should be present and profound; the fetus should present facial petechiae and subconjunctival hemorrhage. ${ }^{10}$

In our study, isolated excessive length of the umbilical cord was found in 8 cases of stillbirths $(19.1 \%)$. This rate remains very high given that the results of the literature review did not include any fetal loss caused by isolated excessive cord length. ${ }^{1}$ However this disorder facilitates travel of the cord and may result in coiling, lateral prolapses and forelying cords with all their consequences. ${ }^{2,10}$

It is quite possible that the stillbirths in our series are due to other funicular abnormalities associated with excess cord length. They could have been unnoticed by lack of diagnostic rigor, given that $63.6 \%$ of patients were followed without ultrasound and no abnormality was diagnosed during follow-up, although many patients received ultrasound in the last quarter. It is the same for abnormal fetal heart rate during labor, bearing in mind that many patients classified as theoretically low-risk give birth without continuous CTG monitoring. However, the possibility of fetal death was found in the study by Djanhan with $0.4 \%$ for knots, and $1 \%$ for breech presentation. ${ }^{1}$

This finding differs from the studies in the literature, where unequivocally fetal death rates were statistically higher when delivery was done vaginally. ${ }^{1,2,10,11,14,15}$ This difference could be explained by the fact that there were many evacuated, often in very poor conditions. So, caesarean section was mostly performed as advocated by Brindeau for maternal rescue, which proves the high number of non-living fetuses after extraction by caesarean section. Moreover, thirteen cases of caesarean section leading to the extraction of fresh stillborn were for reason of abruptio placentae $(86.7 \%)$, and among vaginally deaths, nine were caused by shortness of cord (which could secondarily be from undiagnosed abruptio placentae, a potential cause of fetal death).

We listed seventeen deaths of fetuses with low birth weight, corresponding to $50 \%$ of stillbirths in our series; and among these deaths ten were preterm $(58.8 \%)$. We have no cases of macrosomia associated with isolated funicular abnormality.

\section{CONCLUSION}

This study has allowed us to find out that the funicular anomaly is a hindrance to successful delivery. They are facilitated by excess of amniotic fluid, prematurity and 
low birth weight. Short and prolapsed umbilical cords indicate factors of poor fetal prognosis. Prolapse is an indication for cesarean section, and just as shortness of the umbilical cord is a maternal morbidity factor. As the saying goes, funicular abnormality bites the newborn and licks the mother.

Funding: No funding sources

Conflict of interest: None declared

Ethical approval: The study was approved by the Institutional Ethics Committee

\section{REFERENCES}

1. Djanhan Y, Doumbia K, Kouakou P. Les anomalies funiculaires : Analyse du pronostic fœtal au cours du travail à la maternité du CHU de Bouaké. Journal de la Sago. 2006;7;1:1-4.

2. Merger R, Levy J, Melchior J. Précis d'obstétrique 6ème édition Paris: Masson. 2001:292-300.

3. Shui KP, Eastman NJ. Coiling of the umbilical cord around the fetal neck J Obstet Gyn Brit Emp. 1957;2;64:227-8.

4. Spellacy WN, Gravem H, Fich RO. The umbilical cord complications of true knots, nuchal coils and cords around the body. Report from the collaborative study of cerebral palsy. Am J Obstet Gynecol. 1966;8,94:1136-42.

5. Cushner IM. Prolapse of the umbilical cord, including a late following-up fetal survivors. Am J Obstet Gynecol. 1961;81:666-80.

6. Bursztein J, Rosa P. Influence de la longueur du cordon ombilical sur la fréquence des circulaires. Bull Soc Roy Belg Gynec Obstet. 1962;32:23-8.
7. Benirschke K, Kaufmann P. Pathology of the human placenta. New York: Springer-Verlag. 1990:180-243.

8. Fox H. Pathology of the placenta. London: WB Saunders; 1978:426-457.

9. Eberst B, Boog G, Marzolf G, Ritter J. L'artère ombilicale unique : à propos de 137 cas. Rev Fr Gynecol. 1979;74:37-40.

10. Fournie A, Connan L, Toffani V. Physiologie et pathologie du cordon ombilical. Encycl Med Chir Gynécologie - Obstétrique 5- 073-A-10.

11. Habarugira P. La procidence du cordon ombilical: Facteurs étiologiques et pronostiques. A propos de 160 cas colligés au service de Gynécologie et d'Obstétrique du CHU de Cocody. Mémoire CES Abidjan; 1993:96.

12. Guikovaty JP, Dellenbach P. Les anomalies du cordon ombilical. Encycl Med Chir Obstet. 1978:7781.

13. Niacadie E. Le circulaire du cordon ombilical: incidences sur le déroulement du travail et sur l'état général du fotus pendant et au décours de la parturition. Thèse de Médecine Abidjan. 1983:482.

14. Dufour P, Vinatier D, Bennani S. Procidence du cordon: Revue de la littérature à propos de 50 observations. J Gynecol Obstet Biol Reprod. 1996;25:841-5.

Cite this article as: Diallo M, Diouf AA, Koulimaya CE, Niang Y, Diallo ACN, Ndiaye MD, et al.

Funiculars anomalies during childbirth: about 562 cases collected in Pikine National Hospital. Int J Reprod Contracept Obstet Gynecol 2016;5:4232-5. 